Jurnal e-GiGi (eG), Volume 2, Nomor 2, Juli-Desember 2014

\title{
GAMBARAN INDIKASI PENCABUTAN GIGI DALAM PERIODE GIGI BERCAMPUR PADA SISWA SMP NEGERI 1 LANGOWAN
}

\author{
${ }^{1}$ Inka J. Fenanlampir \\ ${ }^{2} \mathrm{Ni}$ Wayan Mariati \\ ${ }^{2}$ Bernat Hutagalung \\ ${ }^{1}$ Mahasiswa Program Studi Pendidikan Dokter Gigi Fakultas Kedokteran \\ Universitas Sam Ratulangi \\ ${ }^{2}$ Program Studi Pendidikan Dokter Gigi Fakultas Kedokteran \\ Universitas Sam Ratulangi \\ Email: Inka_fenanlampir@yahoo.com
}

\begin{abstract}
Tooth extraction is a process of alveolar dental expenditure, where the tooth is already not possible care anymore. Tooth period is a period of transition when mixed with the date and time of the growth of baby teeth and permanent teeth is considered as vulnerable age and become determinants The purpose of this study was to describe the periods of tooth indication at mixed period on student of SMP Negeri 1 Langowan. Descriptive cross-sectional study with a sample size of 257 students was employed using stratified random sampling technique. The results showed that students who have an indication of tooth extraction on the persistence of mixed tooth period is about 36 students (14\%) and students who have dental caries which is an indication of the revocation period is relatively large mixed with 149 students (57.9\%). Remained tooth root as indicative of the rest of the students in the revocation mixed period with relatively small teeth it about149 students $(25.2 \%)$ and the percentage of supernumerary teeth is an indication of the students in the revocation period is relatively small mixed is about 7 students (2.7\%).
\end{abstract}

Keywords: indication of tooth extraction, tooth mixed period.

\begin{abstract}
Abstrak: Pencabutan gigi merupakan suatu proses pengeluaran gigi dari alveolus, dimana pada gigi tersebut sudah tidak dapat dilakukan perawatan lagi. Periode gigi bercampur yaitu masa peralihan saat tanggalnya gigi susu dan saat tumbuhnya gigi tetap dan merupakan usia yang dianggap rawan dan penentu. Tujuan penelitian ini untuk mengetahui gambaran indikasi pencabutan gigi dalam periode gigi bercampur pada siswa SMP Negeri 1 Langowan. Penelitian ini bersifat deskriptif dengan cross sectional study dengan jumlah sampel sebanyak 257 siswa yang diambil dengan teknik Stratified random sampling.Hasil penelitian menunjukkan bahwa siswa yang memiliki indikasi pencabutan gigi persistensi pada periode gigi bercampur sebesar 36 siswa (14\%) dan siswa yang memiliki gigi karies yang merupakan indikasi pencabutan pada periode gigi bercampur sebesar yaitu 149 siswa (57,9\%). Pada persentase sisa akar yang merupakan indikasi pencabutan pada siswa dalam periode gigi bercampur yaitu sebesar 149 siswa (25,2\%) dan persentase supernumerary teeth yang merupakan indikasi pencabutan pada siswa dalam periode gigi bercampur sebesar 7 siswa (2,7\%).
\end{abstract}

Kata kunci: indikasi pencabutan gigi, periode gigi bercampur

Pembangunan bidang kesehatan gigi dan mulut pada dasarnya ditujukan untuk meningkatkan kesadaran, kemauan dan kemampuan hidup sehat bagi setiap orang untuk mewujudkan derajat kesehatan yang optimal oleh karena derajat kesehatan mempunyai pengaruh yang sangat besar terhadap sumber daya manusia. 1,2

Upaya pemberian pelayanan kesehatan gigi dan mulut pada masyarakat umumnya berupa pencabutan gigi. Tindakan pencabutan gigi merupakan hal yang sering 
dilakukan oleh seorang dokter gigi pada praktik sehari-hari. Tindakan ini merupakan hal yang biasa dilakukan dengan prosedur rutin pada pasien, oleh karena pencabutan gigi merupakan cara termudah dan terbaik untuk menghilangkan sakit gigi apabila gigi tersebut tidak dapat dipertahankan lagi.,

Siswa Sekolah Menengah Pertama merupakan puncaknya periode gigi bercampur karena berada pada usia 11-13 tahun dengan tanggalnya gigi susu dan bertumbuhnya gigi caninus atas, premolar dan molar kedua. Dengan berakhirnya periode gigi bercampur ini, para siswa sebenarnya harus mengetahui keadaan giginya karena kelainan-kelainan gigi yang telah terjadi pada masa periode gigi bercampur harus segera dilakukan perawatan untuk mencegah kelainan gigi yang lebih parah.

Penelitian yang pernah dilakukan kepada siswa Sekolah Menengah Pertama di Kota Bandung pada tahun 2011 didapatkan bahwa berbagai kelainan gigi geligi yang ditemukan pada siswa Sekolah Menengah Pertama yang berada pada masa periode gigi bercampur. Kelainan yang paling umum ditemui yaitu maloklusi yang disebabkan karena persistensi dari gigi susu yang tidak dicabut, gigi karies serta adanya supernumerary teeth pada beberapa siswa. Pada keadaan ini pencabutan gigi merupakan salah satu solusi dari kelainan-kelainan gigi yang telah terjadi. ${ }^{5}$

Survei awal yang telah dilakukan di Sekolah Menengah Pertama Negeri 1 Langowan yang merupakan salah satu Sekolah Menengah Pertama di Kota Langowan Provinsi Sulawesi Utara didapatkan bahwa berbagai kelainankelainan gigi dan mulut seperti karang gigi, gigi berjejal, gigi diastema, gigi karies, gusi bengkak karena gigi karies dan berbagai kelainan lainnya yang mungkin disebabkan oleh karena gigi yang telah karies profunda, sisa akar, persistensi maupun adanya supernumerary teeth yang tidak dicabut.

Hasil survei awal yang telah dilakukan kepada beberapa siswa di Sekolah Menengah Pertama Negeri 1 Langowan ini, dapat diketahui bahwa berbagai kelainankelainan gigi dan mulutnya yang harus segera dilakukan perawatan apalagi pada siswa Sekolah Menengah Pertama merupakan puncaknya pertumbuhan periode gigi bercampur, sehingga kelainan-kelainan gigi dan mulut yang telah terbentuk selama periode gigi bercampur dapat dideteksi dan dapat segera dilakukan perawatan.

Sekolah Menengah Pertama Negeri 1 Langowan yang berada di Kota Langowan merupakan sekolah dengan jumlah siswa terbanyak di Kota Langowan dan daerah ini merupakan daerah yang sementara berkembang pesat di provinsi Sulawesi Utara dari segi perekonomian dan infrastruktur.

Berdasarkan latar belakang di atas, maka penulis merasa perlu untuk melakukan penelitian deskriptif mengenai gambaran indikasi pencabutan gigi dalam periode gigi bercampur pada siswa Sekolah Menengah Pertama Negeri 1 Langowan.

\section{BAHAN DAN METODE}

Penelitian yang dilakukan yaitu penelitian deksriptif dengan menggunakan pendekatan desain penelitian cross sectional study. Penelitian ini dilaksanakan di SMP Negeri 1 Langowan pada bulan Mei-Juni 2014. Populasi penelitian yaitu seluruh siswa SMP Negeri 2 Langowan usia 11-13 tahun yang berjumlah 730 siswa. Sampel pada penelitian ini seharusnya sebanyak 259 siswa orang berdasarkan perhitungan Slovin, namun tersisa 257 siwa karena 2 siswa di drop out, teknik pengambilan sampel menggunakan teknik Stratified Random Sampling. Data diolah berdasarkan distribusi frekuensi dan disajikan dalam bentuk tabel yang di analisis secara deskriptif berdasarkan hasil persentase.

\section{HASIL PENELITIAN}

Pada penelitian ini, indikasi pencabutan gigi dalam periode gigi bercampur ditentukan melalui pemeriksaan mengetahui angka kejadian dari persistensi, karies gigi, sisa akar, supernumerary teeth menggunakan odontogram. Data mengenai distribusi responden berdasarkan indikasi 
Fenanlampir, Mariati, Hutagalung; Gambaran Indikasi Pencabutan Gigi...

pencabutan gigi dalam periode gigi bercampur, dapat dilihat pada tabel berikut:

Tabel 1. Distribusi siswa menurut jenis kelamin

\begin{tabular}{lccc}
\hline Tingkat Pengetahuan & Skor Rata-rata & Jumlah (n) & Presentase (\%) \\
\hline Pengetahuan baik & 29,7 & 69 & 84,1 \\
Pengetahuan sedang & 24,5 & 13 & 15,9 \\
Pengetahuan kurang & 0 & 0 & 0 \\
$\quad$ Total & 54,2 & 82 & 100 \\
\hline
\end{tabular}

Tabel 2. Distribusi siswa menurut umur

\begin{tabular}{|c|c|c|}
\hline \multirow[t]{2}{*}{ Kelompok Umur } & \multicolumn{2}{|c|}{ Banyaknya Siswa } \\
\hline & $\mathrm{n}$ & $\%$ \\
\hline 11 tahun & 41 & 15,9 \\
\hline 12 tahun & 112 & 43,6 \\
\hline 13 tahun & 104 & 40,4 \\
\hline Jumlah & 257 & 100 \\
\hline
\end{tabular}

Tabel 3. Distribusi indikasi pencabutan gigi persistensi dalam periode gigi Bercampur

\begin{tabular}{cccc}
\hline Kelas & Sampel & Persistensi & $\%$ \\
\hline VII & 102 & 21 & 20,6 \\
VIII & 106 & 11 & 10,3 \\
IX & 49 & 4 & 8,1 \\
Jumlah & 257 & 36 & 14,0 \\
\hline
\end{tabular}

Tabel 4. Distribusi indikasi pencabutan gigi karies dalam periode gigi Bercampur

\begin{tabular}{cccc}
\hline Kelas & Sampel & $\mathrm{n}$ & Karies \\
& & 54 & 52,9 \\
VII & 102 & 63 & 59,4 \\
VIII & 106 & 32 & 65,3 \\
IX & 49 & 149 & 57,9 \\
Jumlah & 257 & & \\
\hline
\end{tabular}

Tabel 5. Distribusi indikasi pencabutan gigi sisa akar dalam periode gigi bercampur

\begin{tabular}{cccc}
\hline Kelas & Sampel & $\mathrm{n}$ & Sisa akar \\
& & 23 & 22,5 \\
VII & 102 & 30 & 28,3 \\
VIII & 106 & 12 & 24,4 \\
IX & 49 & 65 & 25,2 \\
Jumlah & 257 & 6 & \\
\hline
\end{tabular}

Tabel 6. Distribusi indikasi pencabutan supernumerary teeth dalam periode gigi bercampur.

\begin{tabular}{cccc}
\hline Kelas & Sampel & \multicolumn{2}{c}{ Supernumerary teeth } \\
& & $\mathrm{n}$ & $\%$ \\
\hline VII & 102 & 4 & 3,9 \\
VIII & 106 & 2 & 1,8 \\
IX & 49 & 1 & 2 \\
Jumlah & 257 & 7 & 2,7 \\
\hline
\end{tabular}




\section{BAHASAN}

Pencabutan gigi merupakan suatu proses pengeluaran gigi dari alveolus, dimana pada gigi tersebut sudah tidak dapat dilakukan perawatan lagi.Tindakan ini merupakan hal yang biasa dilakukan dengan prosedur rutin pada pasien, oleh karena pencabutan gigi merupakan cara termudah dan terbaik untuk menghilangkan sakit gigi apabila gigi tersebut tidak dapat dipertahankan lagi. ${ }^{6}$

Pada periode ini banyak ditemukan kelainan gigi geligi diantaranya maloklusi yang disebabkan karena persistensi dari gigi susu yang tidak dicabut, gigi karies serta adanya supernumerary teeth pada beberapa siswa. Pada keadaan ini pencabutan gigi merupakan salah satu solusi dari kelainankelainan gigi yang telah terjadi. $^{7}$

Gambaran hasil penelitian di siswa SMP Negeri 1 Langowan menunjukkan bahwa dari 257 sampel terdapat 44,3\% siswa yang berjenis kelamin laki-laki dan $55,7 \%$ siswa yang berjenis kelamin perempuan. Dari hasil penelitian menunjukkan pula bahwa kelompok umur 11 tahun merupakan sampel terbanyak dalam penelitian ini yaitu sebesar 43,6 \%. Hasil penelitian ini sejalan dengan penelitian Risca Barel di RSGM Universitas Jember tahun 2013 bahwa kelompok umur 10-12 memiliki prevalensi yang tinggi untuk perawatan gigi dan mulut pada periode gigi bercampur, yaitu sebesar 35,2 \% meskipun di temui perbedaan tempat penelitian dimana Risca Barel mengambil tempat penelitian di RSGM Universitas Jember tahun 2013, sedangkan pada penelitian ini mengambil tempat di anak sekolah menengah pertama. ${ }^{8}$ Pada siswa yang memiliki umur 11 tahun merupakan puncaknya masa peralihan saat tanggalnya gigi susu dan saat tumbuhnya gigi tetap sehingga merupakan usia yang dianggap rawan dan penentu. Kelainan dan kerusakan yang telah terdeksi harus dengan segera dilakukan perawatan agar supaya kelainan dan kerusakan tersebut tidak akan berlanjut. Berbagai perawatan yang dapat dilakukan dalam periode gigi bercampur yang salah satunya adalah pencabutan gigi. ${ }^{9,10}$ pencabutan gigi persistensi dalam periode gigi bercampur menunjukkan bahwa indikasi pencabutan gigi persistensi pada siswa SMP Negeri 1 Langowan dalam periode gigi bercampur tergolong kecil karena dari 257 siswa terdapat $14 \%$ yang memiliki gigi persistensi. Hasil penelitian ini dapat di bandingkan dengan Risca Barel di RSGM Universitas Jember tahun 2013 mendapatkan bahwa kasus pencabutan gigi persistensi pada periode gigi bercampur lebih sedikit dibandingkan dengan perawatan pencegahan dan kuratif yakni sebesar 28,4\%. ${ }^{8}$ Hasil yang berbeda dilaporkan oleh Rilly Ngangi di Balai Pengobatan Rumah Sakit Gigi dan Mulut Universitas Sam Ratulangi tahun 2012 yang menunjukkan bahwa kasus pencabutan persistensi Merupakan kasus terbanyak pada anak-anak yaitu sebesar $62,89 \% .^{11}$

Kelompok umur pada penelitian ini yaitu 11-13 tahun menunjukkan bahwa prevalensi persistensi hanya sedikit, sehingga hal ini dapat menunjukkan pula bahwa prevalensi persistensi kebanyakan berada di kelompok umur $<11$ tahun. Hal ini biasa disebabkan karena pada kelompok umur 11-13 tahun berada pada masa pra remaja sehingga tingkat pengetahuan terhadap kesehatan gigi dan mulut lebih baik dibandingkan dengan kelompok umur $<11$ tahun serta pada kelompok umur 11-13 tahun memiliki kemauan untuk melakukan pencabutan gigi yang sudah goyang pada dokter gigi ataupun dicabut sendiri. Persistensi dapat menyebabkan gigi berjejal, gigi diastema serta berbagai kelainan lainnya sehingga pencabutan harus segera dilakukan. ${ }^{5}$

Berdasarkan penelitian yang telah dilakukan, didapatkan bahwa gigi karies yang merupakan indikasi pencabutan pada siswa SMP Negeri 1 Langowan dalam periode gigi bercampur tergolong besar karena terdapat 57,9\% siswa yang memiliki gigi karies. Hasil penelitian ini mendapatkan perbandingan dengan penelitian Fadhil 
Ulhum di RSGM Universitas Hasanudin Makasar tahun 2010 yang mengemukakan bahwa karies gigi merupakan salah satu indikasi pencabutan gigi yaitu sebesar 31,9\%. Tingginya prevalensi gigi karies yang memiliki indikasi pencabutan pada siswa SMP Negeri 1 Langowan mungkin dipengaruhi oleh berbagai faktor diantaranya oral hygiene yang buruk, kesadaran akan merawat gigi yang kurang, kurangnya dental health education (DHE), faktor ekonomi keluarga serta berbagai faktor lainnya.

Menurut World Health Organization (WHO) di dunia, 60-90 \% dari anak usia sekolah mengalami kerusakan gigi. ${ }^{12}$ Laporan Riset Kesehatan Dasar (RISKESDAS) tahun 2013, mengemukakan bahwa terjadi peningkatan karies aktif pada penduduk Indonesia dibandingkan tahun 2007 lalu, yaitu dari 43,4\% (2007) menjadi 53,2\% (2013). Suatu peningkatan yang cukup tinggi jika dilihat dari besaran kesehatan masyarakat. Data RISKESDAS menunjukkan bahwa terjadi peningkatan karies aktif yang sangat siginifikan pada masyarakat di Provinsi Sulawesi Utara yaitu dari 47,4\% pada tahun 2007 menjadi 57\% pada tahun 2013. Hal ini berarti kebutuhan perawatan gigi masyarakat Sulawesi Utara sangat tinggi namun kesadaran mereka untuk melakukan perawatan gigi masih sangat kurang. ${ }^{13}$

Penelitian ini juga menunjukkan bahwa indikasi pencabutan sisa akar gigi dalam periode gigi bercampur pada siswa SMP Negeri 1 Langowan yaitu sebesar 25,2\%. Pada penelitian Risca Barel di RSGM Universitas Jember tahun 2013 yang menunjukkan bahwa pencabutan gigi sisa akar pada periode gigi bercampur sebesar 18,1\%. Sedangkan penelitian dari Fadhil Ulhum di RSGM Universitas Hasanudin Makasar tahun 2010 yang mengemukakan bahwa sisa akar merupakan indikasi pencabutan gigi yaitu sebesar 38,4\%.

Sisa akar merupakan keadaan hilangnya mahkota gigi oleh karena karies yang telah menghancurkan email gigi sehingga hanya tersisa akar gigi. Sisa akar gigi tidak baik untuk rahang, gusi dan juga kesehatan lainnya. Sisa akar gigi memicu pertumbuhan bakteri yang dapat menyerang jaringan dan pembuluh darah gigi yang menyebabkan beberapa penyakit seperti radang gusi, kista, tumor dan lain sebagainya. ${ }^{13}$

Berdasarkan penelitian yang telah dilakukan, bahwa indikasi pencabutan supernumerary teeth pada siswa SMP Negeri 1 Langowan dalam periode gigi bercampur tergolong kecil karena hanya sebesar 2,7\% dari siswa yang memiliki supernumerary teeth. Hal ini dapat dibandingkan dengan penelitian Safra Azhari di Bogor tahun 2010 bahwa pada anak usia sekolah yang memiliki supernumerary teeth sebesar 1,7\%. ${ }^{14}$ penelitan lain tentang supernumerary teeth di laporkan oleh Rilly Ngangi di Balai Pengobatan Rumah Sakit Gigi dan Mulut Universitas Sam Ratulangi Manado tahun 2012 yang menunjukkan bahwa pasien yang memiliki indikasi pencabutan supernumerary teeth sebesar $0,14 \%{ }^{8}$

Berbagai masalah yang dapat dimunculkan pada keadaan supernumerary teeth yaitu diantaranya susunan gigi tidak rapi, mengganggu estetik terutama apabila gigi ini terdapat pada bagian depan, gangguan tumbuhnya gigi tetap, abses pada jaringan pendukung dan berbagai masalah lainnya. Oleh karenaitu, pada keadaan supernumerary teeth di indikasikan untuk pencabutan gigi. ${ }^{13}$

Siswa Sekolah Menengah Pertama merupakan puncaknya periode gigi bercampur. Periode gigi bercampur yaitu masa peralihan saat tanggalnya gigi susu dan saat tumbuhnya gigi tetap dan merupakan usia yang dianggap rawan dan penentu.

\section{SIMPULAN}

Dari penelitian ini dapat disimpulkan bahwa persentase gigi persistensi yang merupakan indikasi pencabutan pada siswa SMP Negeri 1 Langowan dalam periode gigi bercampur sebesar 14\%. Persentase gigi karies yang merupakan indikasi pencabutan pada siswa SMP Negeri 1 Langowan dalam periode gigi bercampur sebesar 57,9\%. Persentase sisa akar yang merupakan indikasi pencabutan pada siswa SMP Negeri 1 Langowan dalam periode gigi bercampur 
sebesar 25,2\%. Persentase supernumerary teeth yang merupakan indikasi pencabutan pada siswa SMP Negeri 1 Langowan dalam periode gigi bercampur sebesar 2,7\%.

\section{SARAN}

Bagi orang tua dan pihak sekolah agar dapat memberikan wawasan dan pengetahuan serta memberikan motivasi kepada siswa/i tentang pentingnya perawatan kesehatan gigi dan mulut sejak dini oleh karena pada periode gigi bercampur merupakan masa peralihan yang rawan terjadi berbagai kelainan gigi/. Perlu pengaktifan kembali UKS/UKG sekolah SMP Negeri 1 Langowan agar dapat membantu mensosialisasikan kepada setiap siswa/i tentang pentingnya menjaga kesehatan gigi dan mulut.

\section{DAFTAR PUSTAKA}

1. Amir A. Hukum Kesehatan. Jakarta: Widya Medika; 2001. h. 1-3.

2. Hanafiah J, Amir A. Etika Kedokteran \& Hukum Kesehatan. Jakarta: Penerbit Buku Kedokteran EGC; 2008 h. 25-8.

3. Fakultas Kedokteran UI. Kapita Selekta Kedokteran. Jakarta: Media Aesculapius; 2005. h. 34-7.

4. Persatuan Ahli Bedah Mulut dan Maksilofasial Indonesia. Tindakan ekstraksi gigi pada pasien dengan penyulit penyakit sistemik. PABMI 2007 Feb;2. h. 72-3.
5. Panawar A. Seputar Kesehatan Gigi dan Mulut. Yogyakarta: Percetakan Andi Offset; 2013. h. 20-4.

6. Suharti C. Ilmu penyakit dalam Jilid II. Jakarta: Fakultas Kedokteran Universitas Indonesia; 2006. h. 37-9.

7. Gandang perkasa A. Perkembangan balita anda. Journal Bandung; 2013.vol 23. hal 5758.

8. Barel Risca. Gambaran Indikasi Perawatan Gigi dan Mulut di RSGM Universitas Jember. Fakultas Kedokteran Gigi Universitas Jember; 2013. (Skripsi).

9. Haryadi W. Pemeriksaan klinis gigi dan mulut. [online]. 2010 [cited 2014 Mar 05]; Available from URL: http://www.rekam kesehatan.com/pemeriksaan-klinis/.

10. Gordon W. Pedersen. Buku ajar praktis bedah mulut. Penerbit Buku Kedokteran EGC; 1996. hal. 102-5.

11. Ngangi Rilly. Gambaran Pencabutan Gigi Di Balai Pengobatan Rumah Sakit Gigi Dan Mulut Universitas Sam Ratulangi. Program Studi Kedokteran Gigi Fakultas Kedokteran Universitas Sam Ratulangi; 2012. (Skripsi).

12. WHO (World Health Organization). Oral Health. [serial online]. 2012 [cited 2013 Apr 9] Available from URL:http://www. who.int/mediacentre/factsheets/fs318/en/

13. Laporan Riset Kesehatan Dasar (RISKESDAS). DEPKES RI. 2013: 127144.

14. Azhari Safra. Hubungan Pengetahuan dan Keadaan Gigi dan Mulut di SMA Negeri 06 Bogor. Univesitas Indonesia; 2010. (Skripsi). 